\title{
EBM
}

ONLINE

\section{Early surgery was better than conservative care for short-term disability and pain in sciatica}

Michael Yelland

Evid. Based Med. 2008;13;185

doi:10.1136/ebm.13.6.185

Updated information and services can be found at:

http://ebm.bmj.com/cgi/content/full/13/6/185

\section{These include:}

Rapid responses You can respond to this article at:

http://ebm.bmj.com/cgi/eletter-submit/13/6/185

Email alerting Receive free email alerts when new articles cite this article - sign up in the box at service the top right corner of the article

Topic collections Articles on similar topics can be found in the following collections

\author{
Radiology (3079 articles) \\ Clinical diagnostic tests (3583 articles) \\ Pain (neurology) (3112 articles) \\ Pain (palliative care) (682 articles) \\ Clinical trials (epidemiology) (3881 articles) \\ Peripheral nerve disease (231 articles) \\ Rehabilitation medicine (5 articles) \\ General practice / family medicine (6935 articles) \\ Musculoskeletal syndromes (1779 articles) \\ Radiology (diagnostics) (2076 articles) \\ Sports and exercise medicine (797 articles) \\ Neuromuscular disease (784 articles)
}

Notes

To order reprints of this article go to:

http://journals.bmj.com/cgi/reprintform

To subscribe to Evidence-Based Medicine go to:

http:/journals.bmj.com/subscriptions/ 


\section{Early surgery was better than conservative care for short-term disability and pain in sciatica}

\section{STUDY DESIGN}

Design: randomised controlled trial.

Allocation: $\{\text { concealed }\}^{*} . \dagger$

Blinding: unblinded. $\dagger$

\section{STUDY QUESTION}

Setting: 9 hospitals in the Netherlands.

Patients: 283 patients 18-65 years of age (mean age 43 y, 66\% men) who had 6-12 weeks of sciatica diagnosed by a neurologist, disc herniation with nerve root compression confirmed by magnetic resonance imaging, and pain distribution and neurological disturbances correlated to the same nerve root. Exclusion criteria included cauda-equina syndrome, severe paresis, same complaints within 12 months, and history of spinal surgery, spinal stenosis, deformity, or severe comorbidity. Intervention: early surgery $(n=141)$, which included removal of disc herniation using a unilateral transflaval approach and removal of loose degenerated disc material, or conservative care $(\mathrm{n}=142)$ provided by family physicians, with consideration of surgery for increasing leg pain and neurological deficit (within 6 mo) or persistent sciatica (after $6 \mathrm{mo}$ ).

Outcomes: included functional disability (23-point Roland disability questionnaire for sciatica, higher score $=$ worse functional status), and leg and low back pain (100 $\mathrm{mm}$ visual analogue scale [VAS], higher scores $=$ worse pain).

Follow-up period: 2 years.

Patient follow-up: $92 \%$ (intention-to-treat analysis).

\section{MAIN RESULTS}

$44 \%$ of the conservative care group had surgery within 2 years. Early surgery improved disability (mean difference $[\mathrm{MD}]$ in Roland score 3.1, CI 1.7 to 4.3), leg pain (MD in VAS 18, CI 12 to 23), and back pain (MD in VAS 11, CI 6 to 17) at 8 weeks and leg pain ( $p=0.05$ ) over 2 years (figure); groups did not differ for disability $(p=0.25)$ or back pain $(p=0.41)$ over 2 years.

\section{CONCLUSION}

In the short term, early surgery reduced disability, leg pain, and back pain more than conservative care in sciatica.

*Information provided by author.

†See glossary.

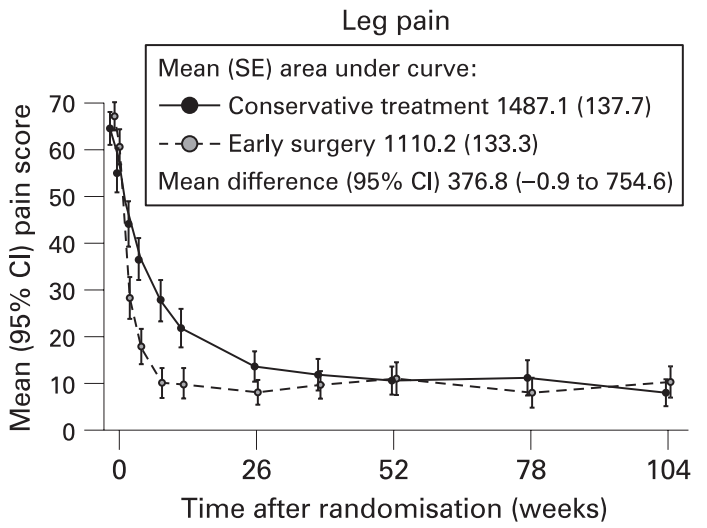

Repeated measurement analysis curves of mean scores for visualanalogue scale for leg pain.

Reproduced with permission from Peul WC, van den Hout WB, Brand R, et al. BMJ 2008;336:1355-8.

\section{ABSTRACTED FROM}

Peul WC, van den Hout WB, Brand R, et al. Prolonged conservative care versus early surgery in patients with sciatica caused by lumbar disc herniation: two year results of a randomised controlled trial. BMJ 2008;336:1355-8.

Correspondence to: Dr W C Peul, Leiden University Medical Centre, Leiden, The Netherlands; w.c.peul@lumc.nl

Sources of funding: Netherlands Organisation for Health Research and Development and Hoelen Foundation, The Hague.

- Clinical impact ratings: GP/FP/Primary care 6/7; Surgery/Orthopaedics 6/7; Surgery/Neurosurgery 5/7
$\mathrm{T}$ he trial by Peul et al helps resolve some of the uncertainty about the role of discectomy in the treatment of sciatica. ${ }^{1}$ It has many messages for clinicians dealing with patients with sciatica due to disc herniation. Although long-term outcomes were similar for both groups, by 12 weeks those treated with early surgery had recovered faster than those treated conservatively (data not reported). This applied not only to leg pain and disability, but also to back pain. Over the ensuing 3-6 months, the early surgery group lost their initial advantage, but delayed surgery was performed in $44 \%$ of the conservative care group by the end of the trial. Unfortunately, $20 \%$ of patients reported unsatisfactory outcomes at 2 years, and $6 \%$ of those who had surgery required repeat surgery within 2 years.

Conservative care was given by family practitioners, who provided analgesia, encouraged mobilisation, and referred patients to physiotherapy or back to hospital as needed. There was no mention of epidural injections, an option that may offer relief for about half of patients during the early stages of sciatica. ${ }^{2}$ This treatment may be less expensive and more acceptable to those who do not want surgery or cannot have surgery for other reasons.

The authors rightly advocate more patient involvement in decision making about surgery because the results suggest that both treatment options are legitimate. Patients with a preference for conservative care can be assured that their long-term outcomes will not be inferior but that surgery may be indicated if their condition worsens. The same applies for those who do not have ready access to early surgery.

\section{Michael Yelland, MD}

Griffith University

Logan City, Queensland, Australia

1. Gibson JN, Waddell G. Cochrane Database Syst Rev 2007;(2):CD001350

2. Buttermann GR. J Bone Joint Surg Am 2004;86-A: 670-9. 